\title{
World Marine Fisheries 1975-2025: Fifty Years of Change
}

\author{
J. S. Beckett \\ 10425 Hyndman Road, R. R. \# 2 \\ Mountain, Ontario, Canada K0E 1S0
}

\begin{abstract}
This paper, as if written in the year 2025, reviews the influences and resulting changes in the marine capture fisheries of the world and in their management during the last quarter of the 20th Century and the first quarter of the 21 st. Influences range from Treaties (such as the United Nations Convention on the Law of the Sea, the Convention on International Trade in Endangered Species, and the Convention on Biological Diversity), Agreements (such as the United Nations Commission for Sustainable Development, and the FAO Code of Conduct for Responsible Fisheries) and public awareness, through environmental and biological events, and the growth of knowledge and the understanding of ecosystems, to factors likely to influence the mix of coastal and distant-water vessels.
\end{abstract}

Keywords: capture fisheries, biology, ecology, International agreements, management

\section{Introduction}

This paper considers the factors currently affecting and likely to affect world fisheries and does so by creating a scenario of world fisheries in 2025 and then suggesting the extent of the various influences in a retrospective manner. Looking back in 2025 over the 50 years of world fisheries since 1975, the relatively small $(11 \%)$ increase in the total catch of marine species at the present time compared to the approximately 80 million tons taken in the mid-1970s, would suggest that little has changed, although harvest values have increased greatly. The apparent stability in catch is illusory, however, as over the period there have been major variations in the marine fish catch with respect to the total amount, the species composition and the contributions from different areas. There was a substantial reduction in total harvest around the turn of the century that reflected falling yields from the stocks under harvest, concerns about certain harvest methods and considerable resistance to the development of new fisheries until more was known about the target species. The recovery since then has been due to a mix of new species, habitat restoration, stock recovery and fuller use of what is actually caught, both of directed species and of bycatches.

The influences during the past 50 years on marine fisheries have been numerous, both in the short and longer term. These influences are examined in the following pages but it is clear that not all have been active in any particular fishery and that the relative importance has been highly variable in different fisheries.

By the mid-1970s, there were already grave concerns about the status of some of the species that had been harvested for centuries. These concerns were, in large measure, the result of the burgeoning fishing power of the world's fleets, in terms of numbers, vessel size and constantly improving harvesting technology. At that time, the third United Nations Conference on the Law of the Sea was underway. The Conference was protracted, consisting of at least one session a year between 1973 and 1982, but it set the stage for the major change in the conduct of fisheries that resulted from extension of Coastal State jurisdiction to 200 miles, particularly in 1977.

The next 20 years up to the mid-1990s, saw these concerns escalate as fish resources were over harvested and ocean climate changes resulted in ecosystem fluctuations that underlined the incompleteness of the scientific understanding of the biological processes involved. During this period, public awareness 
of fisheries issues increased greatly and public pressure was effective in closing or curtailing a number of fisheries that were considered to be unacceptable usually on environmental grounds, but sometimes also as a result of perceptions that the harvest methods were unethical. This awareness developed as part of general concern about the status of terrestrial and freshwater ecosystems and about the overall impact of human activity on the global biosphere. Against this background there were a number of different initiatives in international law, in science and in the way that we treat our natural resources, that have been the foundation for the developments during the first 25 years of this, the 21 st Century.

\section{The Major Influences}

Environment. The dominant influences on world fisheries have been the persistent climatic changes, somewhat masked as they have been by year to year fluctuations, due mainly to shifts in the atmospheric pressure patterns and hence ocean currents, with resultant shifts in primary and secondary production. A further factor in these changes has been increased ultra violet radiation due to ozone depletion. These influences have been expressed in the biological ecosystem as alteration in the relative abundance of different species and in marked changes in the geographical distribution of some major species.

Another long-standing category of major influences has been the alternative uses (other than fisheries) of the marine and coastal environment, such as industrial development, urban growth, recreation and shipping. In more recent years, however, there has been greater understanding of how these influences affect the resources and coastal productivity so that, during the past 25-35 years, the focus has been on holistic approaches to habitat use, and the challenge has been to prevent any further loss of productivity.

Pollution of the marine environment has caused loss of biological productivity, as well as causing health issues with respect to certain fisheries products and closure of certain local fisheries. These elements have been of much less significance in recent years due to the increased awareness of the problems and the action taken to address aquatic pollution at the source.

Human Attitudes. The conviction that living marine resources were inexhaustible took a long time to die, particularly in the minds of many of those that harvested the resources, and still lingered at the start of the 21 st Century. This meant that attempts to conserve the resource by managing the fisheries were often not accepted readily and fishers attempted to circumvent regulations and controls.

Many national and international agencies were involved in fisheries management from the mid-1900s but additional impetus was given during the 1970s and onwards by the development of "ecosystem awareness" outside the fisheries field, stimulated initially by concerns about human impact on the terrestrial environment and about pollution in general. The spread of public awareness to the marine environment was boosted in the 1970s by campaigns against the harvesting of the great whales, some of which were at very low population levels as the result of excessive harvesting. Added impetus came from campaigns against sealing, largely because of the perceived cruelty of the harvesting method (clubbing) and fostered by misplaced concerns about population status. Public involvement developed further to address specific fisheries and harvesting methods, as more information became available on the by-catches of marine mammals, and of other species that caught the public eye, such as seabirds. While these concerns may initially have been about species survival, the realization that much of the marine harvest was wasted gave rise to more concern, and to a broadening of the focus to include harvesting methods in general, catch specificity and exploitation rates. Harvesting levels, in particular, entered into public accounting with the down turn in many traditional North American and European fisheries in the late-1980s and 1990s (FAO, 1995a, and annual updates).

A convergent public concern addressed habitat destruction, and was fed by the damage done to sensitive habitats such as mangrove swamps and coral reefs by urban (and tourist) development, by aquaculture and by abusive fishing practices (cyanide, explosives etc.). Thus by the time the unexpected and dramatic declines occurred in traditional fish resources (FAO, 1995a), there was already considerable 
debate as to whether harvesting methods per se were harmful due to their physical impacts, irrespective of the extent of the harvest. In particular, some fishing gears such as dredges and rakes were known to disrupt the bottom, but there was little quantitative information as to what this meant for the ecosystems.

The public interest focused considerable attention on how scientific information was developed and how it was used in the management of fisheries. At one time, neither the scientific analyses nor the management decision process were open to public scrutiny, but this changed as both those being managed and the general public demanded all information that was available and a role in the decision making process.

The public pressure has been effective in several ways, but mainly through stimulation of public opinion as it impacts political awareness of desirable policies, and through consumer purchasing power. This power has been exerted in both a positive way with preference for products deemed, for example, to have been harvested in an "environmentally friendly" way, or negatively as in boycotting products from, for example, a certain country or fishery.

These public pressures became more and more influential in the last decade of the 20th Century and were very significant in the evolution of fisheries management philosophy and methods. Much of this evolution occurred in the international arena where negotiations of new arrangements provided the forum for divergent viewpoints to be heard, to a much greater degree than did, at that time, national decision making processes.

International Instruments. The United Nations Conference on the Human Environment held in Stockholm in 1972 (United Nations, 1972), and the protracted Third United Nations Conference on the Law of the Sea (UNCLOS) that ran from 1973 to 1982 (United Nations, 1983), provided the background for international fisheries developments during the 1970s and 1980s. The Convention that resulted from the Third UNCLOS was not placed for signature until 1982, but by 1975 , most of the provisions that referred to fisheries were already formulated and by then it was clear that most Coastal States would shortly be extending their jurisdictions to 200 miles, in advance of the formal treaty. Catches from traditional marine fisheries had been falling worldwide due to over-exploitation, and the extension of jurisdiction resulted in even greater reductions in harvest as more conservative management measures were introduced and distance water fleets bore the brunt of the cutbacks in harvesting (FAO, 1995a). Fishing opportunities for foreign fleets continued to decline as Coastal States developed their own capabilities, or allowed access for only certain distant-water fishing partners. The pressure to maintain catch levels led to situations that were not covered fully by the Law of the Sea text, and resulted also in fisheries concerns becoming a much more important element in international negotiations.

The Brundtland Commission in the report "Our Common Future" (World Commission on Environment and Development, 1987) coined the phrase "sustainable development", and in 1992, twenty years after the Stockholm Conference, the United Nations Conference on the Environment and Development (UNCED), the "United Nations Earth Summit" in Rio de Janeiro, Brazil, build upon this by adopting an action plan titled "Agenda 21" (United Nations, 1992), and establishing the Commission on Sustainable Development which still meets annually to review progress in implementing Agenda 21. A second major output of UNCED was the Convention on Biological Diversity (UNEP, 1994) that created an obligation to preserve biodiversity at the genetic, species and ecosystem level.

Other major developments in international fisheries negotiations during the 1990s were the Agreement to Promote Compliance with International Conservation and Management Measure by Fishing Vessels on the High Seas (FAO, 1995b), the United Nations Agreement on Straddling Stocks and Highly Migratory Stocks (United Nations, 1995) ${ }^{1}$, and the FAO Code of Conduct on Responsible Fishing (FAO,

\footnotetext{
${ }^{1} 1995$ Agreement for the Implementation of the Provisions of the United Nations Convention on the Law of the Sea of 10 December 1982 relating to the Conservation and Management of straddling Fish Stocks and Highly Migratory Fish Stocks
} 
1995c). Perhaps the greatest impact of these latter two instruments, and of the BioDiversity Convention, was to codify the concept of caution in making decisions that affect biological resources. This recognition of the need to "look before leaping" and if it was not possible to predict the result with reasonable certainty, to be cautious in the leap, remains a touchstone of fisheries management today. There is still debate over how the "precautionary approach" should be implemented, particularly with regard to grandfathering traditional fishing methods and to initiating exploitation of resources not previously harvested.

A second component that was common to the agreements, addressed dispute settlement, and with respect to the fisheries agreements, the enforcement of rules and regulations, including the rights of third party states to inspect fishing vessels flying the flags of other states. Furthermore, the United Nations Agreement on Straddling Stocks and Highly Migratory Stocks, contained the first clear provisions with respect to actions that could be taken by inspecting states in the absence of responses from the flag state, should a major infringement of international regulations be suspected. This element has been addressed further in a number of international meetings this century (21st) including the several attempts to work out greater control of the harvest of the biological resources of the deep seabed.

Concerns about the population status of certain species and whether there is a risk of extinction can lead, and have led, to fisheries matters being raised in international fora that are not directly concerned with fisheries matters, such as the Conferences of the Parties to CITES (the Convention on International Trade in Endangered Species of Wild Fauna and Flora), and the Convention on Biological Diversity as well as to species being listed in the IUCN (World Conservation Union) Red List of Threatened and Endangered Species (IUCN, 1996 and subsequent editions).

Over the years, other international bodies have also examined fisheries issues, such as the OECD (Organization for Economic Cooperation and Development), and the CEC (the Commission for Environmental Cooperation), while regional fisheries agreements continued to proliferate in the early years of the 21 st Century.

Scientific Uncertainty. The decline in global resources in the 1980s and 1990s and the unexpected collapse of certain fisheries during the 1990s (FAO, 1995a), in the northern oceans, created considerable turmoil in science, besides the major disruptions to fisheries and communities. The causes of the declines are still debated and researched, and generally are considered to have been often due to a combination of factors, including excessive harvesting, abusive fishing practices, ocean climate changes and ecosystem changes.

The events indicated the need for more understanding of the resources and their ecosystems. Recognition that overfishing had been a major component in most stock declines, generated a call for better science in order to predict the impacts of harvesting on the target resources, on associated species and on habitat. Concerns about predator/prey relationships and associated concerns about biodiversity created considerable pressure for more research into ecosystem functioning. Another major factor has been the environmental element, where changes in physical oceanographic factors have led to significant alteration in biological productivity and the relative abundance of different species. Changes in ocean climate have included both year to year features such as El Nino Southern Oscillation events, and longer-term variations that were not associated with clear signals in the physical environment. Overall these events have focused a lot of scientific attention on integrating the knowledge about ocean physics, chemistry and biology.

Concurrent with the resource declines of the 1980s and 1990s, and in part due to them, there was worldwide demand for more open science, particularly with respect to findings relevant to decisions on environmental and resource management. Indeed, much of the demand was fueled by public desire to understand the scientific basis for management decisions and to hold the decision-makers responsible for their actions. 
Competition for Access. This category of influence includes a number of somewhat disparate elements, ranging from the competing aspirations of different users at the national scale, such as aquaculturists seeking brood stock and feed, the recreational sector seeking plentiful large fish, and the different, themselves often competing, sectors of the harvesting industry, to the competition at the international level. It is this latter element that has had major effects on the world's fishing fleets, both in terms of the size of national fleets and in terms of vessel characteristics. The various influences have been national aspirations for revenue and food supply; the general reduction in harvesting rates consistent with sustainable harvest, and the utilization of previously unexploited stocks, (both in accordance with the precautionary principle); changes in harvesting technology both through technical advance and in response to biodiversity and sustainable fishing concerns; the consumer demand in some countries for high quality products; the consumer demand in some countries for any food product; measures to reduce post-harvest loss; and the interplay with sources of cultured fish as these effect the economics of harvesting.

\section{Responses}

Management Philosophies. It is here that the 21 st Century has been most influenced by the events at the close of the 20th Century. The modern universal use of safe biological limits and other guidelines for determining management measures, coupled with very detailed collection of data, is the result of a long process that received an initial boost from the 1995 UN Agreement on Straddling Stocks and Highly Migratory Stocks (United Nations, 1995) and the FAO Code of Conduct for Responsible Fisheries (FAO, 1995). The unexpected still happens, although less often than in the past, or perhaps this is because the downturns in availability can now be better foreseen. The pace of the unexpected did not slow very much in the early-2000s despite the expectations when imposing the new world management regimes envisaged in the 1995 UN Agreement on Straddling Stocks and Migratory Stocks and the FAO Code of Conduct (in its original form). As we now know, or think we do, this was because those early versions of biological limits took too little note of multi-species and ecosystem events. Indeed, it could be argued that it was these continuing surprises that convinced many doubters of the wisdom of the Precautionary Approach.

There is little question however, that a major factor in achieving good fisheries management worldwide has been the expansion of the range of factors that are taken into account, so that policy options and alternative management measures are evaluated not simply on biological grounds but also on an economic and societal basis, with due consideration of what is possible and practical. National and international rules and regulations are now developed cooperatively by those with the management authority and those who are subject to the provisions. The result is a series of measure that are understood and accepted by all parties, and can thus be implemented effectively.

The open discussion of fisheries management options with all interested parties has contributed greatly to the effectiveness of the management systems, with much of the monitoring and control being undertaken by the participants themselves. This in itself has fostered the delegation of much of the decision making process to the smallest practical unit. Individual communities are managing resources that are relatively stationary or are managing a component of a larger fishery, with much less cost to the overall system than used to be the case.

International Arrangements. There are now no areas where fishing is carried out beyond the zone of coastal jurisdiction that are not covered by some form of international agreement on fisheries management. This is in marked contrast to the situation in the 1990s, where despite the existence of many international organizations responsible for fisheries, there were major gaps in area, and more importantly, biological coverage (e.g. most resources of the High Seas beyond the edge of the continental shelves). The organizations tended to focus on traditional species and to be slow to adjust to new fisheries, whether for these species or for species not exploited previously. Perhaps the greatest impetus to address the gaps appears to have been a series of classical "boom and bust" fisheries in deep water, the concerns about exploitation of rare life forms for pharmaceutical raw materials and the precautionary approach that has been discussed already. 
A particular stimulus to the expansion of the management jurisdiction of the various regional agencies was the concern about exploitation of low productivity life forms, particularly those on the deep seabed, as raw material for pharmaceutical research and production. While synthetic production generally followed discovery of any pharmaceutically active ingredient, there were some products that defied this and led to repeated harvesting, often with clear adverse effects on the species and its habitat. The several United Nations debates and conferences on the subject, supported by activities associated with the Commission on Sustainable Development and the Convention on Biological Diversity (United Nations, 1995 and UNEP, 1994), led eventually to the incorporation of provisions to protect these life forms within existing regional bodies rather than the creation of any new body.

The boom and bust fisheries, in which as soon as a new fishing opportunity was discovered, massive harvesting effort moved in and rapidly depleted the resource, focused very considerable attention on the absence of rational fisheries management. In consequence, existing conventions and agreements were either expanded to cover any new fishery, or new international instruments were established. Indeed, a few years ago there were many more such agreements but recently there has been considerable consolidation to reduce costs and duplication.

Initiatives to increase the efficiency of international fisheries management have included a much greater sharing of information between the various agencies, including vessel registration, reports on infractions of regulations whether proven or suspected, vessel sightings, catch reports and landing records. Most Coastal States around the world are now cooperating with these programs and as a result, any competent authority can extract a full record of catch and position for any vessel for the year, and thus detect anomalies in the reports, especially when matched with sighting and inspection information.

Protected Areas. The present pattern of protected areas, ranging from no-take zones to the much larger number of areas where only certain activities are prohibited, has developed in response to the concerns about biodiversity conservation and habitat damage, both of which achieved high public profile in the 1990s to 2000s. These concerns have subsided somewhat as improved methods of examining the bottom flora and fauna have shown that fishing activities were not uniformly spread over the fishing grounds and left untouched much more of the grounds than had been expected. This meant that in situ preservation of typical biotypes was less problematical than had been realized. If this had not been found to be the case, "no-use" areas would need to be more numerous and extensive to meet the objective of preserving examples of all natural habitats. Preservation of "reservoirs" of undisturbed habitat has been facilitated by proscribing the use of certain types of fishing gear from certain areas both to protect bottom habitats sensitive to disruption and to avoid high incidental harvests. The argument as to whether all sensitive habitats should be protected still lingers, despite the demonstration that for a number of bottom types, total productivity remains largely unaltered as a result of fishing activity, although there are substantial species shifts. This has led to the current practice of protecting some examples of these bottom types, but not all of them.

Seasonal closures during spawning aggregations have come and gone and come again, partly as the scientific evidence about the impacts of harvesting at this stage of the life cycle has swung back and forth between uncertainty and firm conclusions and partly as a function of the need to manage discrete components of stock complexes. The fact that spawning closures were implemented, even where there was no firm evidence of impact, appears to have had as much to do with controlling harvest levels at times where the catch rates were highest, as to do with the precautionary approach. The fishing industry complained loudly about the creation of institutional inefficiencies and the added costs of harvesting at other times of the year, but the longer fishing season actually appear to have been beneficial, particularly as market preference for fresh, unfrozen product increased. Furthermore, from a resource conservation aspect, the continuing development of real time methods of discriminating stock components has meant that mixed fisheries can be better controlled with respect to components requiring special protection. In this regard, it is thus no longer necessary to harvest only when the spawning components have separated out from each other. On the other hand, the adoption of more conservative harvesting rates has reduced concern about harvesting stocks at spawning time when the product being sought requires fully mature animals. 
Fishing Gear. The fishing industry has made major advances in addressing many of the criticisms aimed at it over the years, including the early lack of selectivity of most harvesting methods, the concerns about habitat damage, and the concerns about abusive fishing practices such as discarding and misreporting.

The search for more and more efficient selectivity of target species and target sizes was intense during the later years of the 20th Century, and significant advances were achieved in terms of eliminating catches of undersized fish and unwanted species. The modern, almost universal, use of selector devices and their variety is the result of constant development since the 1980s. The importance of size selectivity due to the fishing gear itself has, however, declined, although this is another debate that is still pursued vigorously. In general, it was accepted eventually that reducing exploitation rates from the high levels of the late 20th century to those that are now the norm, meant that the biological requirements for sustainable fisheries were largely met as these rates allowed survival of adequate numbers of fish to maintain the spawning stock. This movement away from a diligent pursuit of the ideal mesh size in particular, has had the advantage of allowing smaller mesh size to be used, and thus avoided the need for different mesh sizes in different fisheries and even in the same fishery in different years. It has also reduced the problem of damage to fish escaping the gear, since some species but by no means all, were shown to be prone to significant mortality as a result of the physical impact of passing through the meshes.

The move away from controlling the minimum mesh size would, however, probably have never been acceptable, given the high profile of the problem, had not the ability increased greatly to detect electronically the size range of fish before fishing commenced, supplemented by electronic sensors and video detection systems in the fishing gear itself to monitor the catch as it is taken. These developments have allowed fishing operations to be targeted on aggregations of larger fish and hence have contributed to the achievement of the biological goal of increasing yield-per-recruit and the economic one of catching larger fish, although these two goals are only compatible up to a point. The fishing industry might prefer fish larger than the sizes providing the maximum yield per recruit in most fisheries, despite lower catch rates, and not only in those examples where the management objectives have recognized this.

These technological developments and some others, were also significant factors in the debate as to whether the use of many of the existing fishing techniques should continue in the new century. There was a great amount of debate about the potential harm to ecosystems and to biodiversity in general, from the perceived indiscriminate harvests of non-target species which were dumped at sea, with very little survival (estimates were that as much as 40 million tons may have been dumped worldwide each year in the 1990s) (Alverson et al., 1994). The major component of this discarding was in the shrimp fisheries, especially in the tropics. Discarding has been addressed by a combination of technical improvements to selector mechanisms, changes in fishing practices (time of day, electrification), avoidance of certain areas and/or seasons, much fuller utilization of the by-catch, and better information on what actually was being caught. There remain uncertainties, even now, but in general the concerns about ecosystem disruption and threats to biodiversity are now much less.

It is perhaps inconceivable in this day and age, but only 30 years ago a number of extraordinary and very destructive harvesting methods and/or techniques were in use. Explosives and cyanide were used on coral reefs to immobilize fish for the aquarium and live fish restaurant trade; large hooks were dragged through schools of fish to snag the catch, with many fish wounded for each one caught; half the catch in some fisheries was discarded because it was of the wrong sex; and gillnets, in particular, might be left for days untended, with much wastage of the catch and indiscriminate harvest.

The use of gillnets does not raise now the concerns that were cited often in the past in many fisheries around the world, given that they are no longer used in areas where marine mammal and sea bird by-catch was a problem, and that they are now either fished in such a way as to avoid other by-catch problems, or they have been banned. Furthermore, where there is risk of losing nets, they are equipped with simple, but effective locator devices to facilitate the mandatory recovery of lost nets. 
A gear type that is now used much more widely than ever in the past, is the livefish trap, particularly in temperate waters. Traditionally a means for harvesting crustacea, and of fish for local use, the trap has gained much more importance as a means of catering to the demand for very fresh product. The fish are either sold alive, or very fresh, or are held in feed-lot operations where they are fattened before being marketed. The various designs of traps for use in offshore waters, coupled with pressurized livefish containment systems and carrier vessels have allowed the trap operations to seek the fish, rather than waiting for the fish to find them, as used to be the case. The fact that this is the only gear type, or only one of a few types, allowed in some protected areas, together with the ability to release by-catch, has provided stimulus to development of innovative designs and handling techniques.

Catch Composition. This is where substantial changes have occurred over the years, one major reason being that although the catches that used to be discarded are now much less, most of what is caught is now landed for human consumption either direct or indirectly after conversion to flour and other food additives, or as feed for aquaculture operations. The current substantial exploitation of oceanic pelagic species, such as the small scombroids, bramids and squids, and the wide range of meso-pelagics, took many years to develop because of the concerns about the impact on higher predators, such as the larger tunas and marine mammals, and the complications of catching such fish on an economic basis. It is likely that these catches will increase as it appears that there are no adverse impacts on the ecosystems as a result of the present levels of controlled harvest.

Harvesting in very deep waters, usually beyond areas of Coastal State jurisdiction, was seen in the late-1990s as an opportunity for the larger fishing vessels displaced from more traditional fisheries, but with some exceptions, this has not proved to be the case. In many instances, catch rates were high initially, vessels flocked in, and the stocks collapsed. It has been argued that a more aggressive approach to management would produce satisfactory results, but the uncertainties about the impacts of doing so remain too great. Indeed, the "boom and bust" fisheries gave considerable impetus to the development of comprehensive regional fisheries management bodies.

As has been noted earlier, the last quarter of the 20th Century was a period in which many of the traditional fisheries declined, in some cases such as the groundfish in the northern oceans, quite dramatically. It would have been very encouraging to the scientists, managers, fishing industry personnel and general public who were involved at that time, to know how well some of these stocks would recover, albeit that the recovery was slow and often is still underway. Catches are well below the peak historic values, of course, since these were often made as a result of pulse fishing previously under-exploited stocks, but it is clear that discarding, misreporting and other abusive fishing practices were major components in causing the declines, particularly those practices that resulted in much higher exploitation rates than were estimated. The implementation of more rigorous controls, including the use of new harvesting techniques, coupled with the worldwide adoption, albeit also slowly, of harvest strategies well below those based on the concept of maximum yield, have allowed recovery where recruitment and overall productivity has permitted.

Superimposed on the geographic pattern of the fisheries and the decline and subsequent slow rebuilding of many traditional species, has been the shifting distributions caused by changes in ocean climate. In general, distributions have been displaced poleward, except where currents from polar or otherwise cooler regions have intensified and species distributions have responded by shifts towards the equator or into deeper water.

The most hotly disputed harvest issue around the world throughout the period has been that of harvesting marine mammals, other than the biggest whale species and the smaller dolphins and porpoises. In the earlier years, this debate included seals, but this is no longer a substantive issue given the information available on population levels, the prohibition on some harvesting methods, and the use of other population control measures in areas where this has proven feasible. A major element, however, has been the realization and acceptance that predators cannot be left to multiply unchecked. The various outbreaks of 
disease in the seal herds have, rather surprisingly, strengthened this understanding, partly perhaps because the severity of the outbreaks appear to have been related to body condition linked to food availability. Most populations of the largest whale species remain at low levels, although despite many dire predictions that were made 30 or 40 years ago, none have gone extinct. At the other end of the marine mammal size range, the complete ban on harvesting dolphins and porpoise became effective in the 2010s. The main issue is the harvest of medium sized and small whales, with the debate continuing between those that contend that they should not be harvested on ethical grounds and those that argue that these species and the food consumed by the ever increasing populations, should be available for harvest. The cycle of renewed hunts, followed by moratoria seems likely to continue.

Fleet Characteristics. The international scramble to exploit the resources of the oceans beyond Coastal State jurisdiction that characterized the later years of the last century continued well into this one. This was due to at least three factors: one being the concept that operation of high seas vessels, catching high priced fish, would automatically bring economic advantage to the flag state; the second being that Coastal States, in responding to the opportunities of expanded fishing zones, generally acquired more harvesting capacity than was needed, so they themselves contributed to increasing pressure on high seas resources, in addition to the foreign effort displaced from their zones; and the third being the reluctance of many distant water fishing nations to cut back their fleets, because of the impacts on both employment and the supply of food, however uneconomic the actual harvesting operations, and the high subsidization needed. Indeed, the high capital costs and energy consumption of larger vessels, when measured in terms of each ton of fish caught, were very much higher than for smaller vessels. The fact that the world fishing capacity was many times that needed to harvest the available resources was further complicated by the desire of shipbuilding nations to maintain productivity in their shipyards. Even where vessels were decommissioned in one country, they often reappeared under a different flag and the practice of fishing under nonmember flags in regulated fisheries was a considerable problem in the 1990s. By the late-1990s, however, non-member fishing activity was reduced greatly as a result of the international agreements of the period, bilateral pressure on so-called "flags of convenience" countries, and some accommodation within regional organizations, of the fishing aspirations of countries that had fleets with only limited harvesting opportunity.

When it happened, the actual reduction in the grossly excessive harvesting capacity was surprisingly rapid. The international pressure to match harvesting capacity to harvesting opportunity, the rapid elimination of uncontrolled high seas fisheries, and the reality of the poor economic performance aggravated by increased operating costs; led to the wholesale decommissioning of large vessels. This process was complemented by technological developments that allowed smaller vessels to be operated in deeper water fisheries and to store their catch for longer periods while still meeting the demand for high product quality. There was some shifting of crews as those previously in distant water fisheries were able to continue fishing on these smaller vessels as replacements for crew members who did not wish to be at sea so long.

There remain some areas under Coastal State control where fisheries are short lived seasonally and foreign fleets are contracted to harvest the catch, usually under arrangements to land at least part of the catch in the Coastal State. The development of the collector vessel concept has been an integral part of these arrangements. These vessels are generally quite small and bring to shore the agreed part of the directed catch, and the incidental harvest that has little value on the world market yet is of value domestically, or land live fish, without requiring the larger vessel to stop fishing. Furthermore this has allowed considerable rationalization of near shore fleets as Coastal States, particularly those with small fisheries zones, have been able to maintain domestic supply without the costs associated with operating a fleet that is viable only seasonally in local waters.

The collector vessel style of operation, coupled with advances in technology to handle and store fish, has had significant impact on the harvest of the smaller pelagic species in waters within 2-3 days steam of onshore facilities. In most cases the vessels are quite small and spend much of the year fishing traditional species, and only become "carriers" at the peak of the seasonal foreign vessel fishery. This has worked 
particularly in situations where substantial fresh fish markets exist close to the distribution points. The other component of this style of operation, the actual fishing unit, has developed into a class of vessel capable of being at sea for considerable periods of time, with only limited fish processing and holding capability, but equipped with a variety of gears and with considerable attention to crew amenities.

In contrast, and particularly where a seasonal pulse in landings would exceed local capacity to assimilate them, the collector factory vessel has remained viable. There are not many of these units, but they travel the world oceans to process the catches of existing fleets during periods when high catches are expected and carry the product to some distant market.

Both the roving harvesting unit supplying shore based processing operations and the collector factory vessel are relatively new components of distant water fleets. There are however, much fewer classical distant water operations these days, in the sense of vessels that are used to harvest and store product for considerable time. Those that do still exist involve modern vessels that are generally very large, unless harvesting high value species such as the tunas, which are still taken by longline from relatively small boats. They operate in remote parts of the world's oceans, particularly areas with hostile weather conditions such as the Southern oceans, or target lesser-valued species, such as bonitos and breams. These latter fisheries, which are quite new and take some 10 million tons a year, are generally prosecuted with very large midwater trawls, equipped with excluder devices for sharks and marine mammals, although the incidental capture of these latter is very infrequent, given the sophisticated target recognition devices available and the mandatory use of mammal scarer devices.

There are few distinct deep water fisheries as a result of the ability of coastal vessels to fish depths of $2000 \mathrm{~m}$, and also because of the distressingly long list of stock collapses that have followed the initiation of such fisheries using large vessels.

Science. With respect to advice on the management of fisheries, the nature of debate is such that it is tempting to think that little has changed, but that would be a simplistic response to the constant demands on science for more certainty in the conclusions and more predictions of future events. The idea that little has changed is fostered by scientists who still, as in the past, emphasize the uncertainty of their conclusions and complain about inadequate funding. Perceptions of uncertainty in the results are to some extent magnified out of proportion by the routine provision of some measure of confidence in any analysis or assessment. These "confidence limits" and the results of risk analysis, appear to emphasize that there is still plenty of room for error, and mean that more allowance for uncertainty is incorporated into management decisions than many in the fisheries industry might wish.

There has in reality, been enormous progress in the scientific understanding of the oceans and their biological process, although, perhaps the greatest disappointment that an observer from 1975 would have about today's scientific understanding of the oceans would be in the status of knowledge about multispecies interactions and predator prey models. Each time an advance appears to be made, some event has occurred which shows that the understanding remains incomplete. An example of the fact that there have been significant advances is the now widely accepted realization that fluctuations in the populations of species at relatively low trophic levels can have major impacts on the populations of other species at all trophic levels, although these cannot, at least as yet, be modeled reliably.

This lack of ability to predict inter-species effects has meant that there has been great caution when proposals have been made to control population levels of species exerting major impact, either directly as in predator-prey situations or through displacement of other species. The reluctance to initiate such deliberate manipulation of populations is also a reflection of the realization that all species groups, including marine mammals, show considerable natural fluctuation over time, irrespective of harvesting and other human influences.

Science has benefited from technological developments, including the miniaturization of sensor packages, which have enhanced the ability to track ocean organisms and to monitor their environment. The 
data from archival tags and pop-up tags, coupled with the continued refinement of genetic discrimination techniques have contributed to a much greater understanding of sub-stock structure, while complicating greatly the management of the fisheries because of the extent of intermixing of stock components in the fishing areas.

The worldwide demands for involvement in fisheries management from the industry, native peoples and the general public have required development of processes to incorporate all forms of knowledge and not simply that from biological investigation. This has resulted in the integration of traditional harvesters, and particularly native peoples, into the scientific process in order to foster assimilation of their knowledge and understanding.

These same demands also required the recognition of the contributions to fisheries management that could be obtained as a result of research into the economic aspects of fisheries and alternative management options, and into institutional behaviour and community stability. All of these inputs have been fostered and encouraged by the refusal of all affected by management decisions to operate under what in the 20th Century was the traditional management process. In these earlier regimes, the decision making process was centralized and the evaluation of the various inputs was carried out in a restricted environment without open debate.

Market Preferences. This is the means by which public perception has caused considerable change in harvesting practices, although public outcry has sometimes achieved results without resorting to product discrimination by buyers. The development of harvesting standards, and their identification in product labeling that started during the late-1990s, has contributed to the elimination of a number of abusive fishing practices and environmentally harmful fisheries worldwide. However, attempts by some factions in society to use market influence to prevent the harvest of marine mammals have never been particularly successful, particularly as public knowledge increased about the escalating populations of some of the species and their ability to out-compete other species groups. Other fisheries have been effected by perception rather than fact, one being the rapid demise of attempts by the aquaculture industry to use bycatches taken in traditional fisheries as a source of feed in their operations. The perception, although it may have had some foundation, was that such use of by-catch would lead to an undermining of attempts to reduce incidental harvest levels.

Other forms of market preference, particularly the usually short lived belief that certain types of food were of special value to a healthy life style, have had significant affect on harvest patterns and even national fishing activities. It is to be regretted that some of these short-term preferences have been the mechanism causing considerable harm to the status of certain species because of the belief that the product was of great medicinal value. Not that this was not true in some cases, but clearly the belief was misplaced in others.

Negative impacts on markets and hence on the fisheries has resulted from scares about pollution and the cases of algal poisons usually associated with shellfish harvest. The latter have given rise to very sophisticated "bloom watch" programs incorporating real time satellite monitoring, as well as at-sea and airborne monitoring and product testing.

\section{Summation}

Today's worldwide network of regional fisheries organizations, coordinating their activities every four years, while sharing data sources on a real time basis through common databases and vessel registration, is the logical, but somewhat surprising, result of much trial and tribulation in the management of ocean fisheries resources. One of the strengths of the coordinated approach, and particularly the universal sanction scheme, that has resulted in violators of regulations in one area being subject to sanctions in all fishing areas worldwide, has been the pressure that has been available to convince one or another national interest to cease attempting to push the edges of the regulatory regime. 
The fishing fleets of today are generally based in the region where they fish, although ranging within the region. There are some fisheries that use very large vessels, but with the exception of those for open ocean small pelagic and meso-pelagic species, these are not extensive.

In general, the management of harvesting has resulted in resource stability within the context of year to year variability in productivity, although ecosystem approaches to management are still somewhat in the form of trial and error. Most stocks and stock complexes that were depleted 25 years ago have rebuilt to a greater or lesser extent or are at levels consistent with decisions that recognize that not all elements can be above those capable of yielding the maximum sustainable yield, without foregoing the harvest of other elements.

It is predictable that fisheries will continue to attract media attention, not only due to developments, natural or otherwise, that effect adversely certain interest groups, but also as a result of unresolved issues such as the harvest of whales, and natural phenomena such as red tides, disease epidemics and extreme climatic conditions that produce unusual events.

\section{References}

ALVERSON, D. L., M. H. FREEBURG, S. A. MURAWSKI, and J. G. POPE. 1994. A global assessment of fisheries by-catch and discards. FAO Fish. Tech. Pap., No. 339.

FAO. 1995a. Review of the State of the World Fishery Resources: Marine Fisheries. FAO Fish. Circ., No. 884. Rome: FAO.

1995b. Agreement to Promote Compliance with International Conservation and Management Measures by Fishing Vessels on the High Seas. Fisheries and Agricultural Organization of the United Nations, Rome.

1995c. Code of Conduct for Responsible Fisheries. Fisheries and Agricultural Organization of the United Nations, Rome.

IUCN. 1996. IUCN Red List of Threatened Animals. IUCN, Gland, Switzerland.

UNITED NATIONS. 1972. United Nations Conference on the Human Environment, Stockholm, 1972. Declaration on the Human Environment.

1983. United Nations Convention on the Law of the Sea, UN Publication E.83.V.5.

1992. United Nations Conference on the Environment and Development. Earth Summit, Rio, 1992.

1995. Agreement for the Implementation of the Provisions of the United Nations Convention on the Law of the Sea of 10 December 1982 relating to the Conservation and Management of Straddling Fish Stocks and Highly Migratory Fish Stocks. 4 Dec. 1995. UN Doc A/Conf.164/37.

UNITED NATIONS ENVIRONMENTAL PROGRAM. 1994. Convention on Biological Diversity. UNEP/ CBD/94/1. WORLD COMMISSION ON ENVIRONMENT AND DEVELOPMENT. 1987. Our Common Future. United Kingdom: Oxford University Press. 